Article

\title{
Who Is Willing to Pay for Online Journalistic Content?
}

\author{
Marju Himma-Kadakas * and Ragne Kõuts \\ Institute of Social Sciences, University of Tartu, 51003 Tartu, Estonia; E-Mails: marju.himma@ut.ee (M.H.-K.), \\ ragne.kouts@ut.ee (R.K.) \\ * Corresponding author
}

Submitted: 30 May 2015 | In Revised Form: 20 August 2015 | Accepted: 28 September 2015 |

Published: 29 December 2015

\begin{abstract}
While the overall readership of newspapers is growing as a result of the multiplatform reach, many online media consumers are not offered the surplus value they expect of journalistic content. Since a great deal of journalistic content published on the internet has been free of charge for years, attempting to monetarise this content is now proving complicated. This article considers the motivating factors behind attitudes towards paying for online journalistic content in different population groups. We follow two directions: attitudes towards paying for online news, and obstacles that compromise willingness to pay in different groups. The survey results and trends noticed by media organisations indicate that the public's readiness to pay for journalistic online content is growing, albeit slowly. Based on the outcomes of various interviews we can conclude that the expectation of exclusive quality and web distinctive content are the two main reasons behind willingness to pay for online journalistic content, however, it is difficult to outline particular preference groups based on cultural, demographic, or socio-economic characteristics. This seems to be the result of audience fragmentation-the reasons behind willingness to pay for online journalistic content are hidden in the interests and preferences of small audience groups.
\end{abstract}

\section{Keywords}

audience studies; media audience; online journalism; paywalls; pricing models; willingness to pay

\section{Issue}

This article is part of the special issue "Turbulences of the Central and Eastern European Media", edited by Epp Lauk (University of Jyväskylä, Finland).

(C) 2015 by the authors; licensee Cogitatio (Lisbon, Portugal). This article is licensed under a Creative Commons Attribution 4.0 International License (CC BY).

\section{Introduction}

The multiplatform reach has increased the overall readership of print media content, however, "combining online and print readership is theoretically problematic because it assumes that each online user delivers the same value as a print reader, which is not the case" (Chyi, Yang, Lewis, \& Zheng, 2010, p. 63). Media enterprises are changing, embracing the innovation of technology and product (Schlesinger \& Doyle, 2014, p. 2), redefining and consolidating business models (Mateo, Bergés, \& Garnatxe, 2010; Teece, 2009), and re-evaluating the audiences' needs and expectations (Herbert \& Thurman, 2007). We can see that the number of individuals who pay for digital news has grown in many countries (Newman \& Levy, 2014, p. 56) and that the preferred payment method is predominantly that of ongoing subscriptions rather than one-off payments (Newman \& Levy, 2014, pp. 56-57). Nevertheless, many online news media users do not get the surplus value they expect as paying customers (Goyanes, 2014).

The New York Times was the first to offer its newspaper content for free in 2001, in a way paving the way for the creation of a 'free culture' in relation to news consumption (Castells, 2006). Social networks have extended the 'free culture' and this has enabled the distribution of free information to a greater degree (Cingel, Lauricella, Wartella, \& Conway, 2014; Jansson \& Lindell, 2015). Therefore, having cultivated the habit of free consumption for over a decade, it is difficult to 
now demand payment for this content. In addition, the "free culture" in the European media environment is, for the most part, complemented by public service media, which is accessible through multiple platforms. Thus, for the individual user a new dilemma emerges: why pay when a vast amount of information is still accessible free-of-charge?

Mobile media reveal some counter-tendencies to the "free culture". According to Newman and Levy (2014) the increasing usage of mobile platforms can be seen as a supporting factor in readers' increased willingness to pay for online news. However, not only technology has influenced consumer behaviour; there are also personal contributing factors. Given that in advanced societies ITC is freely accessible to everyday users (Eurostat, 2015), economic factors are not emphasised, making it even more relevant to show what individual considerations lie behind the decision to pay for digital journalistic content. To date, the factors influencing willingness to pay have been sought in readers' sociodemographic background and media consumption habits (Curtois et al., 2015; Goyanes, 2014, 2015; Herbert \& Thurman, 2007). Indeed, we can summarise the results of these studies very simply-the factors related to the decision to pay are still unclear and multifold.

The arousal of media interest could be dependent on social factors, which can be described in terms of social situation i.e. the situation in which information is applied for and used (Katz, Blumer, \& Gurevitch, 1973, Wilson, 2006). Firstly, social factors create tensions and a sense of conflict that an individual can ease by consuming mass media products. Secondly, social factors create a heightened degree of awareness in relation to problems that demand attention and further information, which can be searched for in the media. Thirdly, the news media acts as a substitute for and supplement to dull everyday life patterns dictated by the social situation. Furthermore, the social situation highlights certain values and creates the expectation that one should be familiar with media considered to be vital for members of the social group in order to build a feeling of togetherness (Katz et al., 1973).

In this article, we will argue that it is not possible to outline the individual, social, and contextual factors that influence willingness to pay for online journalistic content, while in the context of audience fragmentation, situational and content factors play the biggest role. The multifold factors mentioned above will be analysed on an individual level with relations to the macro level by utilising the uses and gratifications approach, and by relating media consumption habits to characteristics of the media systems (Peruško, Vozab, \& Čuvalo, 2013, 2015). Thus, in the next chapters we will provide context for an analysis based on the three related areas: media systems as the background that explains media content made available in specific countries, different pricing models applied to online journalistic content, and the audience members' preferences in relation to online journalistic consumption. On this basis, empirical material collected in Estonia will be presented.

\subsection{Media System as a Background for Media Usage}

For the last ten years, media systems research has been based on the exhaustive model offered by Hallin and Mancini $(2004,2012)$, which relates social political context to the media system in particular countries. Specifics in Europe include, amongst others, "the significant position still occupied by public service broadcasting, the high status still often attributed to print and print journalism in the spectrum of mass media, and the continued attachment to protectionist measures, exceptional for global markets" (McQuail, 2007, pp. 20-21). On the other hand, the 'Europeanization' of media markets takes place- "the EU and other Europe-wide bodies try to achieve a more open market for media goods and services" (McQuail, 2007, p. 21). Thus, the pressure not to give "free lunches" to audiences also follows.

In line with the structuration theory, there have been some attempts at defining audience behaviour patterns according to the media systems model (Peruško et al., 2013; Yuan \& Ksiazek, 2011; Webster, 2009). Peruško et al. (2015) documented the impact of macro-level institutional structures on micro-audience practices, stating that various digital media systems have a significant effect on all aspects of media use. Peruško et al. tested Hallin and Mancini's model (2004) with a cluster analysis of media system variables and found that many CEE post-socialist European democracies "do cluster together with the countries grouped in the Mediterranean polarized pluralist model" (Peruško et al., 2013, p. 148). Estonia is similar to the "Northern" group where media usage is characterized by a higher usage of printed newspapers, internet and social networks and by a greater radio audience (Peruško et al., 2013). On the other hand, a liberal approach to market regulation characterises the context of media use in Estonia (Örnebring, 2011, p. 30), and Peruško et al. (2013, p. 138) deduce that the practices of media audiences will have an impact on media systems themselves.

On the other hand, news consumption on the internet depends on ICT accessibility for different populations. There seem to be no economical obstacles for ICT usage in Europe, however living standards in CEE countries are lower in relation to older European Union countries. Only in Bulgaria does the level of internet access in households fall to below 60 per cent, with all other CEE countries presenting much higher levels (in Estonia the level of internet access is 83 per cent). It is also relevant to note that lower living standards are often compensated by much cheaper communication services, which are clearly less expensive than the EUaverage (Eurostat, 2015). 


\subsection{Pricing Journalistic Content}

Five of the twelve business models described by Art Silverblatt (2009) also apply to the Estonian media landscape. According to the first model, the "free model", information available through the internet is free-of-charge and accessible to everyone, thus media producers do not receive any profit from online news. This, presently in Estonia, is only partly valid, as charged content exists in parallel to free content, while similar "free models" are in use in other CEE countries (e.g. Latvia, Lithuania, Slovenia, Serbia, Croatia etc.). Gradually, different media enterprises are starting to use the "fremium" pricing model, according to which some of the content is free, while some of the content is only accessible through a paywall.

Freely available products do not force the user to consider whether or not to pay. In turn, free products send the message of a lower value product, and this may decrease the user's interest in the product. The mental cost, combined with the financial cost of a product diminishes the probability that a customer might accept a micro-payment model, especially when rival options are free-of-charge (Sindik \& Graybeal, 2011). This certainly does not mean that public service media should not offer content free-of-charge, rather, it means that the monetarised content needs to be different and should be aimed at target audiences who are willing to pay.

Over the last couple of years, Estonian news media organisations have started to introduce different content pricing models. The dominant model is "fremium", according to which the journalistic content is differentiated and some of it-mainly immediate and timely news content-is offered free-of-charge; while other content, mostly newspaper content or content that is specially produced for the online channel, is only accessible via paywall. There are differences in the exploitation of pricing models by the two biggest news websites (www.postimees.ee and www.delfi.ee), news websites that focus mainly on finance and business (www.aripaev.ee) and the company that manages a system of local and regional newspapers (Ühinenud Ajalehed/Joint Newspapers).

The biggest and most dominant online news edition, Delfi.ee, still functions on an advertising-funded, so called "free" business model, according to which the number of user page views are exchanged for a reciprocal amount of the advertisers' money, and the same model is also used by Postimees.ee, the second biggest online news provider in Estonia. In recent years, both of these content providers have started to introduce the "fremium" model, according to which some of the content (mainly content from daily newspapers owned by the same company-Eesti Päevaleht for delfi.ee and Postimees for postimees.ee) is behind a paywall. The same fremium model has also been introduced by the financial daily Äripäev and was adopted by the Joint Newspapers company for an initial period.

From this trend we can see how the systematic pricing of journalistic content is becoming commonplace in Estonian news media enterprises. The managing directors of Postimees and Joint Newspapers see the audience's paying contribution as an inevitable course of action for media enterprises as they are unable to finance the quality content that the audience expects solely through revenues earned from advertising (interview with the managing directors), and see the pricing of content as an instrument that will adjust the audience's consumption habits (interview with the managing director of Postimees, Mart Luik). All of the managing directors expressed a belief that in the near future the pricing of digital content will increase turnover and that the number of users willing to pay will continue to grow. In reality, the growth in audience so far has met these expectations, now the main challenge lies in how to engage new audience segments and at what price.

There is a difference in engaging the everyday news audience segments of delfi.ee and postimees.ee, and the financial news audience of aripaev.ee. The managing director of Äripäev explains that 90 per cent of the potential audience for his media channel has already been reached (interview with managing director of Äripäev, Igor Rõtov), but now the question to be answered is what would encourage the audience to pay more for different products. In his opinion, a possible solution for niche audiences could be the premium model, according to which all content, both in printed newspapers and online, would be priced (interviews with managing director of Äripäev, Igor Rõtov, and Joint Newspapers, Margus Mets).

Joint Newspapers has switched from the fremium model to what is almost a premium model, which means that over 90 per cent of the content is behind a paywall. Their audience can be categorised as nicheusers with a special interest in hyper local topics. Similarly, on its business website, the Joint Newspapers company does not focus on engaging new audience segments as the limited audience is already engaged. In this case, the main goal is to maintain the audience that is already paying, and it is for this reason that local newspapers differentiate between newspaper and online content, offering content produced exclusively for online channels.

Aiming at niche audiences with special interests seems to be a direction that all media enterprises are following as it enables them to charge for a variety of products that hold relevance for different audience segmentations.

According to interviews with the respective managing directors, it can be said that expanding the product selection (e.g. special content for digital newspapers, conferences, participation in special interest clubs), 
and integrating different news organisations (e.g. online editions, local and nation-wide newspapers, publishing houses), is one developmental direction that media enterprises are following in order to renew their business models. In the long term, this may have an impact on the media system and in turn, could support the relationship between the media system and a shift in audiences' consumption habits, as is suggested by Peruško et al. (2013, 2015).

You have free content and you accustom people with this solution. Then you start to offer some content that is valuable. Gradually, they will see the value of content and are willing to pay the proper price for it. (Mart Luik, managing director of Postimees)

Nation-wide news portals like Postimees.ee and Delfi.ee differentiate between different content categories by putting a higher price on products that are known to engage a considerably higher number of users.

\subsection{Reluctance and Willingness to Pay for Journalistic Content}

There has been contradictory argumentation on the topic of willingness to pay for online journalistic content (Dutta, 2012; Herbert \& Thurman, 2007; Hermansson, 2013). Largely, reluctance to pay does not necessarily depend on personal income. The empirical study by H. I. Chyi et al. (2010), which focused on the citizens of Hong Kong, made it clear that people with a higher income were more likely to be unwilling to pay for digital news. A study of the audience that pays for digital media content revealed that $35 \%$ are aged $55+, 52 \%$ have higher education qualifications, $89 \%$ say they are very interested in news, $43 \%$ use a tablet for news, and lastly, as an example, in the UK the main reason for signing up and remaining a digital media reader is the broad range of news coverage offered (Newman \& Levy, 2014, pp. 56-57).

Goyanes (2014, p. 751) argues that users who are engaged in moderate use of Twitter were more likely to pay for online news than users who had never used Twitter, but there are no significant differences between non-Twitter users and heavy Twitter users in relation to their willingness to pay for online content. He also argues that some Twitter users employ this social network as an alternative to paid online news. Herbert \& Thurman (2007, p. 211) note that charging for content has largely been considered impossible given the high precedent of failed attempts. But they present the example of iTunes for buying digital media content as a parallel for distinctive online newspaper content that could encourage large numbers of users to spend money. This said, the growing availability of free news via social network sites will continue to change the au- dience's behaviour in the future. It will definitely change people's understanding of what the news represents and, in the situation where news is everywhere on the internet, the behaviour patterns they adopt in order to avoid news (Velsker \& Kõuts, forthcoming).

Being aware of the factors that influence users' willingness to pay is important for media organisations when developing new business models, as well as when predicting potential changes in the role of journalism in democratic society. According to Martin Engebretsen (2006, p. 68), the reader has different expectations that need to be satisfied on either a conscious or subconscious level: they are looking for variety and entertainment, they want to be assured that the world today is still roughly the same it was yesterday and they are trying to find a connection between solutions for problems they often experience with others. Routine and habits are of undeniable importance in understanding media consumption (Courtois, Schrøder, \& Kobbernagel, 2015). An individual's decision as to whether or not it is worth paying for journalistic content depends not only on personal interests, habits and previous experiences, but also on exact situations and the influence of his/her peers. In order to become a part of an individual's news diet, a news medium must 1) be worth the time spent, 2) be acceptable to peer networks, 3) maintain a public connection, 4) have participatory potential, 5) be affordable in terms of price, 6) have technological appeal, and 7) offer a situational fit (Courtois et al., 2015, p. 125). In the context where media organisations try to monetarise journalistic content on a multi-platform level, it is essential to know what the audience is willing to pay for. In this context, payment goes beyond the act of a monetary contribution-as Davenport and Beck (2001) remark, the struggle to engage audiences' attention is becoming more and more difficult, and they predict that the growing perception of the attention economy will emerge (Davenport \& Beck, 2001, pp. 210-211).

Both the attention economy approach and the audience's expectation of added value (Jankowski \& van Selm, 2000) present a challenge for the production of digital journalistic content. Paying for news would mean that the user appreciates what is being offered more and would read and record it more diligently, while for an advertiser, this would make the product more valuable (Anderson, 2009, referenced by Sindik \& Graybeal, 2011).

According to Salovaara and Juzefovics (2012), more often than not, online media channels mediate news gathered from other sources without adding any surplus value, and news sites on the internet are generally overloaded with press releases, material produced by news agencies and references to other online news portals and newspapers. Slovenia and Serbia, two CEE countries similar to Estonia, reveal similar drawbacks in relation to online news media content. The analysis of 
online multimedia formats indicates a lack of the knowledge required to format multimedia information properly and exploit internet possibilities to the fullest (Vobič, 2011; Vobič \& Milojević, 2014). The example of Slovenia does not differ from the Greek example (Spyridou \& Veglis, 2008) or the German company, welt.de (Brandstetter \& Schmalhofer, 2014), whose paywall protected information segment offers no content of added value in terms of the medium's technical possibilities.

Loit and Siibak (2013, p. 25) consider that the emergence of digital media has increased the volume of news produced, and that this increase has not improved, but rather contributed to the deterioration of news quality. As expressed following the advent of online news media (Boczkowski, 2004; Dahlgren, 1996; Deuze, 2004; Pavlik, 2000), the hope that online media would provide valid competition to printed media and bring about historical technological changes in journalism, has not materialised. Online journalistic content lacks the universally approved criteria that define journalistic quality and the technological level expected by audiences.

According to data provided by the Reuters Institute for Digital News Reports, the most intriguing topics for readers include national and international news, and news relative to their hometowns, while the proportion of interest in entertainment news differs largely between varying age groups (Newman \& Levy, 2014 p. 13). It is up to the reader to decide what content is relevant to his/her personal sphere: online content could be more versatile than printed content, but it often overlaps with other editions and is lacking in terms of quality as well as in terms of information selection criteria. From a reader's point of view, there is an important question to be answered-is web content worth paying for?

On the basis of these points, the research questions of this study are:

RQ 1: Is there a socio-demographic profile that defines those who are willing to pay for online journalistic content?

RQ 2: What factors compromise willingness to pay for online journalistic content in different audience groups?

\subsection{Method of Study}

This article maps out factors that promote or compromise willingness to pay for online journalistic content, as presented by online media users. We use data collected in $2011(\mathrm{~N}=1510)$ and $2014(\mathrm{~N}=1503)$ by the Estonian quantitative survey Mina.Maailm.Meedia $(\mathrm{MeeMa})^{1}$ to show what motivates willingness to pay

${ }^{1}$ This work was supported by institutional research funding IUT 20-38 from the Estonian Ministry of Education and Research. and the factors that compromise willingness to pay amongst different socio-demographic groups in Estonia. In order to gain insight into individual reasons behind different users' willingness to pay, we conducted 13 qualitative semi-structured interviews with active online media consumers. All interviews in this study were conducted between March 2014 and March 2015.

Combining quantitative methods (to answer research question 1) and qualitative methods (to answer research question 2) helped us to gain insight into the reasons behind users' willingness to pay as quantitative data analysis alone would not have answered our research question, but without quantitative data, the interviews would have been devoid of a broader context.

\section{Results}

In the past, different research projects have provided controversial results regarding digital media consumers' willingness to pay for online journalistic content, with these results successfully demonstrating how quantitative research alone cannot provide a clear socio-demographic profile of the people who are willing to pay for online news media content, and our quantitative data analysis emphasising the point. Comparing answers to the question "are you willing to pay for online content", it is evident that between 2011 and 2014 the number of people who have adopted a firm position in relation to their willingness to pay for online journalistic content has increased (see Table 1). In 2011, 37 per cent of the people questioned had no clear standpoint as to whether or not they would be willing to pay for news content; however, by 2014 this figure had dropped to $24 \%$.

Table 1. Answers to the question "Are you willing to pay for online content?" in 2011 and 2014 among Estonian population (Sources: MeeMa database 2011, 2014).

\begin{tabular}{lll}
\hline & $\mathbf{2 0 1 1}(\mathbf{N}=\mathbf{1 5 8 3})$ & $\mathbf{2 0 1 4} \mathbf{( N = 1 5 0 3 )}$ \\
\hline Yes & $17 \%$ & $7 \%$ \\
Don't know & $37 \%$ & $24 \%$ \\
No & $46 \%$ & $69 \%$ \\
\hline
\end{tabular}

Based on the surveys in 2011 and 2014 it can be said that willingness to pay for online content is not correlated to the economic situation of respondents. For instance, only 15 per cent of the respondents say that they cannot afford to buy a computer or access to internet (MeeMa database, 2014). Therefore it can be concluded, that reasons other than purely economical factors motivate users' willingness to pay for online journalistic content.

This said, the aspect of quality is relevant as according to the 2011 data, 17 per cent of respondents stated that they would be willing to pay more for Estonian newspapers if these media channels could present quality information (MeeMa database, 2011). This also 
follows the main reasoning of news providers, who claim that charging readers could improve the quality of the news offered. Even so, 50 per cent of MeeMa 2011 respondents were of the opinion that online news should be completely free, even if the quality could be improved through payment.

Our regular representative survey data indicates that users' willingness to pay for news media is not related to their income, interests or media consumption habits (Vihalemm, Lauristin, \& Kõuts, 2012), to how much they trust different media channels (Kõuts, Vihalemm, \& Lauristin, 2013) or to their critical perception of journalism or need for information (MeeMa, 2011, 2014). Willingness to pay does not appear to be related to anything that would be observable through a quantitative survey.

On the other hand, while quality is an important criterion, seeking to improve the quality of news content is not necessarily the only factor capable of guaranteeing the financial interests of media entrepreneurs. Moreover, the constraint of mapping factors that influence users' willingness to pay lies in the fact that quality is a fuzzy concept and the meaning of quality varies from individual to individual. What is considered as 'quality' for a media enterprise may not denote 'quality' for different audience segments or individual consumers.

\subsection{Willingness to Pay}

After acknowledging that even the most comprehensive survey questionnaires cannot answer the question as to who would be prepared to pay for online content, we conducted semi-structured interviews with selected audience members. The interviewees of our study were separated into two groups: one with a general level of interest in news and a second with a specific interest in finance. Both groups expressed their willingness to pay for online content, though only about third had actually paid for it.

Interviewees stated that they would be willing to pay for online content, as it is a service, just like a newspaper or any other media product that a media organisation charges for, with their main argumentation regarding quality being that the good things in life are never free. This general sentiment emphasises the belief that it is reasonable to pay in order to access news content which meets higher quality standards than free news content, however, it follows that a superior level of journalism is expected from priced news. Checked facts, separate-entities in relation to opinions and facts, and balanced information were among the examples cited, while the definition of the quality of priced news involved both content and formal preferences.

At least it seems that quality control and editing are somewhat more efficient for priced news. Maybe there is less sheer nonsense. (M4)
For the respondents, quality is one of the central factors that influences their willingness to pay. Quality is the value a reader expects from a newspaper, but he/she now also expects it from digital news. From this perspective, one can partly conclude that the pricing of digital media increases the quality of its content for the reader, as the priced product is perceived to contain content of a higher quality than that offered by its freeof-charge counterparts. This, in a way, matches the presumption of media entrepreneurs that the audience expresses its expectations and preferences through their willingness to pay.

\subsection{1. "Something Extra"}

The use of medium specific possibilities is important to users. The interviewees all cited examples of immediacy, multi-mediality, and hyper-textuality as "extras" employed by online news media. In relation to free-ofcharge and priced online news, the respondents highlighted the aspects of speed and immediacy, however some compromise on speed was accepted when it comes to priced content, as it was recognised that the compilation of comprehensive content takes longer and reinforces the criterion of quality.

However, these "extras" are not the sole elements that motivate willingness to pay. Immediacy, which is considered an important value for news reporting, not only in the case of emergencies, but also in the timeous delivery of urgent everyday news, is not necessarily the main factor that motivated the interviewees to pay for content. Indeed, some respondents differentiated the freshness of information, including breaking news regarding war events, accidents, disasters etc., from more significant, in-depth studies and accurate content.

When there is news that Siim Kallas wants to become the Prime Minister, I would rather not see news every half an hour about it, I would like to read a proper analysis on whether he wants or does not want to become the Prime Minister. (M4)

The reader's loyalty and consumption habits appear to stem from this reasoning. Readers are more willing to pay for content produced by a media edition that also provides them with immediate information during critical situations, which-and this was a crucial condition-is free. Thus, it can be concluded that readers' habits and their loyalty to a channel that encompasses both free-of-charge and priced information, greatly affects their willingness to pay for digital content.

The use of web-specific features are considered to offer surplus value and exclusiveness, while the content is expected to have been produced especially for the online edition of that specific news portal. Web features and exclusive content are of paramount im- 
portance to the reader in terms of the information quality of online content. For example, the interviewees remarked on the importance of length and the richness of the story, revealing that people are more willing to read long and informative texts online as these stories reflect the work-effort of the media organisation. This in itself is slightly contrary to the so far relatively widespread notion that online readers are looking for quick information and therefore shorter texts are better suited for online editions.

\subsubsection{A Personal Connection}

A personal connection with a particular topic or field of interest is one of the most relevant factors that motivates people to pay for the content. According to the interviews, one of the essential values of both free and priced digital content is the readers' personal connection to the topic. This sort of personal connection can be divided into two spheres. The first involves information associated with the readers' home region or that of close relatives (geographical and personal proximity to the topic). For example, a cancer-survivor is interested in stories about cancer and its treatment, hyper local topics from their hometown and topics of specific special interest.

The second involves work-related information, which is largely specific to the field of the particular person's occupation. This was something many interviewees mentioned in relation to their news content preferences. The consumers are attracted by their own personal interest in work-related news and a humane approach to the subject; however, it is vital that news is presented in an intriguing manner in order to lure the reader's attention, especially when he/she is considering whether or not to pay for content.

Still, the reader finds it important, that his or her interest areas would be covered and that he or she would not receive too much information he or she has no interest in:

I would be willing to pay if someone made an app that would allow me to set which topics interest me and the noise would be removed! (N8)

Instead of wasting time on finding a free, and possibly useless alternative, consumers may decide that the convenience of immediately accessing the desired content is the biggest advantage of paying for content. (Wang, Zhang, Richard Ye, \& Nguyen, 2005) This was something one of the interviewees pointed out, saying that often one's motivation to pay arises from the wish to receive pre-selected information and save time by eliminating the need to sift through news that is of no particular interest. The pre-determined selection of news by the news provider could save time, but that would mean the online edition should shift its focus towards releasing only important information instead of what is considered trivial news.

\subsubsection{Niche Audience: Investors}

Five of the interviewees were investors by profession and their media consumption habits were analysed with their special interest in financial topics in mind. During these interviews, three common points were raised:

1) the interviewees expressed their willingness to pay (WTP) for online content that offers an exhaustive approach to financial topics and contains reliable information, which in turn could be profitable for their professional practice;

2) the price of the acquired unit may be significantly higher than regular journalistic content for products that supplement the media product;

3) pricing content was considered as an essential condition to providing quality information on investing, and paying for the content or the product is perceived as a 'key' that permits one to access privileged information.

All five investors had paid subscriptions for financial newspapers, investing portals and private financial advice forums, for which the monthly or yearly subscription or membership fees were remarkably higher than those of other platforms offering journalistic content in Estonia. Their special interest in and the possibility of profiting from the information provided were the main factors influencing the WTP of this niche audience.

Interviewees expressed their readiness to pay for supplemented products linked to journalistic content. For example, there is a "media product" that Äripäev uses to provide ideas related to the field of investment and reflect best practice concepts. This product consists of an imaginary investor called Toomas, whose investment practice is analysed through real outcomes. All of the interviewees knew about Investor Toomas and regarded him as an expert consultant specialised in investment activities. This sort of quality advice is also seen as one of the additional products that could satisfy the special interests of a specific audience segment. Therefore, defining the quality of journalistic content and additional media products depends on specific interests, but this quality is seen as being worthy of the elevated price.

\subsection{Obstacles that Compromise Willingness to Pay for Online Journalistic Content}

Obstacles that compromise willingness to pay for online content are closely connected to factors that influence willingness to pay. This means that obstacles are often outlined by the defining factors that contrib- 
ute to other users' willingness to pay, marking these factors as ambivalent indicators.

\subsubsection{The Lack of "Something Extra"}

The main obstacle that one encounters in relation to users' willingness to pay is related to the surplus value of online content:

I do not see the additional value that the priced digital news would have compared to the content of public broadcasting that is free and trustworthy. What is it that I pay for, what do I get more from there? (M5)

Presenting something "extra" that adds surplus value to the online content is important, and particularly in connection with the price of the content. Similarly, media entrepreneurs note that users also consider a low price to be an indicator of inferior quality. In fact, one of the interviewees expressed the notion that if the price is too low, the newsroom cannot provide quality. Cross-media content with added benefits is something that increases the value of the available information and makes it specific for the web as a medium.

For the money I pay I'd like to see that someone has produced something special. The fact that good reportage videos or photos are published seems to be too ordinary; I wouldn't like to pay too much extra for this, but if someone did something really "'extra", that would be worth paying for. (M5)

\subsubsection{The Habit of "Free"}

There is also the additional factor of saving money, which is usually mentioned in relation to the practice or habit of not paying for news media content and supports Castells' idea of a "free culture" (2006). Many of the interviewees mentioned that they enjoy public service media content that is free of advertisements and free-of-charge. This brings us to the conclusion that the 'free culture' is not only promoted by a rise in the consumption of information published on social media networks, but that it is supported by PSM, even on a media systems level.

In addition, the medium itself also seems to influence media consumption habits. People who are accustomed to reading the newspaper prefer media content that is similar or similarly formatted to that of a newspaper, even when presented on the web, meaning that the information needs to be free of distracting advertisements. However, in turn this condition works against the media enterprise's interest in selling audience reach to advertisers.

One of the main arguments given in support of not paying for online journalistic content is the fact that so much information can easily be accessed free-ofcharge via online search engines, and therefore, the referred or aggregated content from other news outlets lowers the value of information.

\section{Conclusions}

Currently, willingness to pay for online journalistic content is of essential relevance as the number of individuals who pay for digital news has grown steadily in many countries (Newman \& Levy, 2014, p. 56), however, there is a need for further study directed at reevaluating the audiences' needs and expectations (Herbert \& Thurman, 2007). In this study we tried to outline individual, social, and contextual factors that influence willingness to pay for online journalistic content.

$R Q$ 1: Is there a socio-demographic profile that defines those who are willing to pay for online journalistic content?

The results of this study reveal that willingness to pay for online journalistic content is growing, if not in a uniform fashion across the board. It is possible to outline different factors that influence willingness to pay, however, these factors are not necessarily related to socio-demographic markers or media consumption habits. The factors that influence willingness to pay are recognisable in small audience segments with specific interests.

$R Q$ 2: What factors compromise willingness to pay for online journalistic content in different audience groups?

In addition to the substantial quality of the information made available, exclusivity, surplus value, and medium specific features-such as animations, video, interactive graphics etc.-, are expected from priced online journalistic content. Factors that compromise users' willingness to pay for content include technical issues such as the complicity of payment methods, while the main hindrance seems to be a lack of surplus value. This means that if the information is easily, and more importantly, freely accessible on the internet, it lowers the value of the journalistic content.

Identifying the expectations and preferences of different audience segments is of vital importance when it comes to understanding whether an audience will be willing to pay for online journalistic content. The factors that influence users' willingness to pay are often mutually interactive and overlap, and are very specific in different audience segments. It is therefore impossible to profile audience preferences through sociodemographic data and there are many limitations presented by the analysis of willingness to pay based solely on quantitative survey data. There may be some in- 
terlinks between media systems and media consumption habits, but these cannot be analysed separately from a qualitative insight into the preferences of different audience segments in relation to each media system.

It must be emphasized that the general level of interest in news is low. This could be explained by a scarcity of journalistic content that fully uses the assets of internet, and by the fact that the motivation to pay for content is usually linked to strong personal motivation and previous experiences of paying for journalistic content. Quite often, interest in journalistic content depends more on personal factors than on elements that journalists can influence (quality, speed, relevance etc.), and given that the subject of interest varies greatly among different audience segments, content providers face a difficult task in satisfying everyone's information needs through the same medium.

\section{Acknowledgements}

The authors would like to thank Merilin Sarapuu and Juhan Lang, both students of the University of Tartu, who contributed their time and effort in conducting the interviews for this research.

\section{Conflict of Interests}

The authors declare no conflict of interests.

\section{References}

Boczkowski, P. J. (2004). The processes of adopting multimedia and interactivity in three online newsrooms. Journal of Communication, 54(2), 197-213.

Brandstetter, B., \& Schmalhofer, J. (2014). Paid content. Journalism Practice, 8(5), 499-507.

Castells, M. (2006). Mobile communication and society: A global perspective. Cambridge: MIT Press.

Chyi, H. I., Yang M. J., Lewis S. C., \& Zheng, N. (2010). Use of and satisfaction with newspaper sites in the local market: Exploring differences between hybrid and online-only users. Journalism and Mass Communication Quarterly, 87(1), 62-83.

Cingel, D. P., Lauricella, A. R., Wartella, E., \& Conway, A. (2014). Predicting social networking site use and online communication practices among adolescents: The role of access and device ownership. Media and Communication, 2(2), 1-30.

Courtois, C., Schrøder, K. C., \& Kobbernagel, C. (2015). Exploring landscapes of news consumption crossnationally. In F. Zeller, C. Ponte, \& B. O'Neill (Eds.), Revitalising audience research: Innovations in European audience research (pp. 123-142). New York, London: Routledge.

Dahlgren, P. (1996). Media logic in cyberspace: Repositioning journalism and its publics. Janvost/The Public,
3(3), 59-72.

Davenport, T. H., \& Beck, J. C. (2001). The attention economy: understanding the new currency of business. Boston: Harvard Business School Press.

Deuze, M. (2004). What is multimedia journalism? Journalism Studies, 5(2), 139-152.

Dutta, S. (2012). Analyzing consumer intention to pay for online content: A systematic approach. Journal of Theoretical and Applied Information Technology, 31(1), 89-102.

Engebretsen, M. (2006). Writing for the web: An introduction to online journalism. Kaunas: Vytauto Didžiojo University Press.

Eurostat. (2015). Information society. Retrieved from http://ec.europa.eu/eurostat/web/informationsociety

Goyanes, M. (2014). An empirical study of factors that influence the willingness to pay for online news. Journalism Practice, 8(6), 742-757.

Goyanes, M. (2015). Apoyo estructural en la intención emprendedora de estudiantes de periodismo y comunicación audiovisual en España. El professional de la información, 24(1), 55-61.

Hallin, D., \& Mancini, P. (2004). Comparing media systems. Cambridge: Cambridge University Press.

Hallin D., \& Mancini P. (Eds.) (2012). Comparing media systems beyond the Western world. Cambridge: Cambridge University Press.

Herbert J., \& Thurman N. (2007). Paid content strategies for news websites. An empirical study of British newspapers' online business models. Journalism Practice, 1(2), 2007

Hermansson, G. (2013). One dollar news: User needs and willingness to pay for digital news content (PhD dissertation). Graduate School of Business and Law, RMIT University, Australia.

Jankowski, N. W., \& van Selm, M. (2000). Traditional news media online: An examination of added values. Communications, 25(1), 85-101.

Jansson, A., \& Lindell, J. (2015). News media consumption in the transmedia age. Journalism Studies, 16(1), 79-96.

Katz, E., Blumer, J. G., \& Gurevitch, M. (1973). Uses and gratification research. The Public Opinion Quarterly, 37(4), 509-523. Retrieved from http://www.jstor. org/stable/2747854?__redirected

Kõuts, R., Vihalemm, P., \& Lauristin, M. (2013). Trust in the context of audience fragmentation. CM: Communication Management Quarterly, 26, 77-102.

Loit, U., \& Siibak. A. (2013). Mapping digital media: Estonia. A report by the open society foundations. Retrieved from http://www.opensocietyfoundations. org/sites/default/files/mapping-digital-mediaestonia-20130903.pdf

Mateo, R., Bergés, L., \& Garnatxe, A. (2010). Crisis, what crisis? The media: business and journalism in times of crisis. tripleC: Communication, Capitalism \& Cri- 
tique, 8(2), 251-274.

McQuail, D (2007). The current state of media governance in Europe. In G. Terzis (Ed.), European media governance: National and regional dimensions (pp. 17-25). Bristol and Chicago: Intellect.

Newman, N., \& Levy, D. A. L. (Eds.) (2014). Reuters Institute digital news report 2014: Tracking the future of news. Oxford: Reuters Institute. Retrieved from: http://www.digitalnewsreport.org

Örnebring, H. (2011). Estonia. A country report for the ERC-funded project on Media and Democracy in Central and Eastern Europe. Retrieved from http:// mde.politics.ox.ac.uk/index.php/country-reports

Pavlik, J. V. (2000). The impact of technology on journalism. Journalism Studies, 1(2), 229-237.

Peruško, Z., Vozab, D., \& Čuvalo, A. (2013). Audiences as a source of agency in media systems: Post-socialist Europe in comparative perspective. Medialni Studia, 2, 137-154.

Peruško, Z., Vozab, D., \& Čuvalo, A. (2015) Digital mediascapes, institutional frameworks, and audience practices across Europe. International Journal of Communication, 9(2015), 342-364.

Salovaara, I., \& J. Juzefovics. (2012). Who pays for good journalism? Journalism Studies, 13(5/6), 763-774.

Schlesinger, P., \& Doyle, G. (2014). From organizational crisis to multi-platform salvation? Creative destruction and the recomposition of news media. Journalism, 16(3), 305-323.

Silverblatt, A. (2009). Business models for a battered journalism industry. St. Lois Journalism Review, 1, 2628.

Sindik, A., \& G. Graybeal (2011). Newspaper micropayments and millennial generation acceptance: A brand loyality perspective. Journal of Media Business Studies, 8(1), 69-85.

Spyridou, L.-P., \& Veglis, A. (2008). Exploring structural interactivity in online newspapers: A look at the Greek web landscape. First Monday. Retrieved from: http://firstmonday.org/htbin/cgiwrap/bin/ojs/index. $\mathrm{php} / \mathrm{fm} /$ article/view/2164/1960

Teece, D. (2009). Dynamic capabilities and strategic management: Organising for innovation and growth. Oxford and New York: Oxford University Press.

Velsker, L., \& Kõuts, R. (forthcoming). How audience is reaching for a contact with traditional media via Facebook.

Vihalemm, P., Lauristin, M., \& Kõuts, R. (2012). Trends in Estonian media landscape in 2000-2012. Media Transformations, 6, 12-63.

Vobič, I. (2011). Online multimedia news in print media: A lack of vision in Slovenia. Journalism, 12(8), 946962.

Vobič, I., \& Milojević, A. (2014). "What we do is not actually journalism": Role negotiations in online departments of two newspapers in Slovenia and Serbia. Journalism, 15(8), 1023-1040.

Wang, L. C., Zhang, Y., Richard Ye, L., \& Nguyen, D.-D. (2005) Subscription to fee-based online services: what makes consumer pay for online content? Journal of Electronic Commerce Reasearch, 6(4).

Webster, J. G. (2009). The role of structure in media choice. In T. Hartman (Ed.), Media Choice, a theoretical and empirical overview (pp. 221-233). New York: Routledge. Retrieved from http://webster.soc.north western.edu/pubs/Webster\%20(2009)\%20Media\%2 OChoice.pdf

Wilson, T. D. (2006). On user studies and information needs. Journal of Documentation, 62(6), 658-670.

Yuan, E. J., \& Ksiazek, T. B. (2011). The duality of structure on China's national television market: A network analysis of audience behavior. Journal of Broadcasting \& Electronic Media, 55(2), 180-197.

\section{About the Authors}
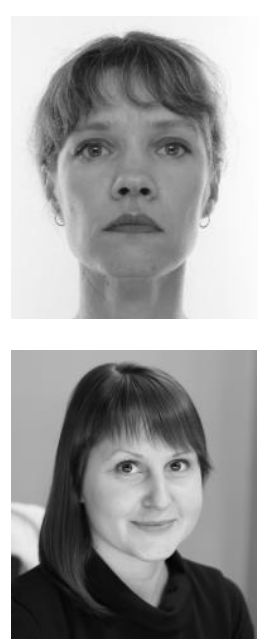

\section{Dr. Ragne Kõuts}

Ragne Kõuts is a lecturer of journalism studies and a manager of the journalism MA programme at the institute of Social Studies of the University of Tartu in Estonia. Her dissertation analysed media content and usage patterns from a systems-theoretical perspective in media-connected society. Her research interests include citizen journalism, changing media use patterns amongst audiences and the role of the mass media in integration. She teaches theories of media and communication and courses on media use and media systems in Europe.

\section{Marju Himma-Kadakas}

Marju Himma-Kadakas is a doctoral student of media and communication at the University of Tartu. Her research focuses on the changing conventions of journalistic practices in relation to online journalism and changing technologies. She teaches courses on news reporting, feature writing, and digital media at the institute of Social Studies. 